\title{
Oxalic acid as a heterogeneous ice nucleus in the upper troposphere and its indirect aerosol effect
}

\author{
B. Zobrist ${ }^{1}$, C. Marcolli ${ }^{1}$, T. Koop ${ }^{2}$, B. P. Luo ${ }^{1}$, D. M. Murphy ${ }^{3}$, U. Lohmann ${ }^{1}$, A. A. Zardini ${ }^{1}$, U. K. Krieger ${ }^{1}$,

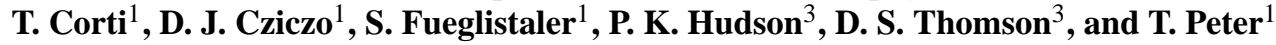 \\ ${ }^{1}$ Institute for Atmospheric and Climate Science, ETH Zurich, Zurich, Switzerland \\ ${ }^{2}$ Department of Chemistry, Bielefeld University, Germany \\ ${ }^{3}$ Earth System Research Laboratory, National Oceanic and Atmospheric Administration, Colorado, USA
}

Received: 1 March 2006 - Published in Atmos. Chem. Phys. Discuss.: 8 May 2006

Revised: 14 July 2006 - Accepted: 23 July 2006 - Published: 27 July 2006

\begin{abstract}
Heterogeneous ice freezing points of aqueous solutions containing various immersed solid dicarboxylic acids (oxalic, adipic, succinic, phthalic and fumaric) have been measured with a differential scanning calorimeter. The results show that only the dihydrate of oxalic acid (OAD) acts as a heterogeneous ice nucleus, with an increase in freezing temperature between 2 and $5 \mathrm{~K}$ depending on solution composition. In several field campaigns, oxalic acid enriched particles have been detected in the upper troposphere with single particle aerosol mass spectrometry. Simulations with a microphysical box model indicate that the presence of OAD may reduce the ice particle number density in cirrus clouds by up to $\sim 50 \%$ when compared to exclusively homogeneous cirrus formation without OAD. Using the ECHAM4 climate model we estimate the global net radiative effect caused by this heterogeneous freezing to result in a cooling as high as $-0.3 \mathrm{Wm}^{-2}$.
\end{abstract}

\section{Introduction}

Cirrus clouds cover about $30 \%$ of the Earth's surface, playing an important role in the chemical and physical processes of the atmosphere. Their presence increases the scattering and absorption of solar radiation as well as the absorption of long wave terrestrial radiation (Baker, 1997). A change in cirrus cloud coverage may significantly alter the global radiation balance and hence the Earth's climate. The exact mechanisms of cirrus cloud formation is still unknown. Ice particles in cirrus clouds can form via homogeneous ice nucleation from liquid aerosols or by heterogeneous ice nucleation on solid ice nuclei (IN). Field observations indicate that IN are involved in the heterogeneous formation of some cirrus clouds (Chen et al., 1998; Cziczo et al., 2004a). Several

Correspondence to: $\mathrm{B}$. Zobrist

(zobrist@env.ethz.ch) laboratory studies have investigated heterogeneous ice nucleation on black carbon (DeMott et al., 1999) or inorganic IN, e.g., solid ( $\left.\mathrm{NH}_{4}\right)_{2} \mathrm{SO}_{4}$ (Zuberi et al., 2001), kaolinite and montmorillonite (Zuberi et al., 2002), hematite and corundum (Hung et al., 2003), aluminum oxide, alumina-silicate and iron oxide (Archuleta et al., 2005).

While the potential of organic aerosol particles to act as cloud condensation nuclei (CCN) has been established for water clouds (Novakov and Penner, 1993; Facchini et al., 1999), their influence on upper tropospheric ice clouds is less well known although they can constitute up to $50 \%$ or more of the dry aerosol mass even in the upper troposphere (UT) (Novakov et al., 1997; Middlebrook et al., 1998; Murphy et al., 1998). Theoretical studies indicate that homogeneous ice nucleation in aerosols containing organics may be impeded (Kärcher and Koop, 2005), in agreement with recent field observations (DeMott et al., 2003; Cziczo et al., 2004b). In contrast, the effect of solid organic IN on heterogeneous ice nucleation processes is largely unexplored. The diversity of organic substances in the atmosphere makes it basically impossible to investigate all potential organic ice nuclei, and poses the need to focus on the most likely candidates. For this purpose, we define three prerequisites for a water soluble organic substance to act as an ice nucleus in upper tropospheric cirrus clouds:

(i) Its abundance in the upper troposphere must be sufficiently high and its volatility sufficiently low to allow the formation of crystals.

(ii) There must be a pathway leading to nucleation of organic crystalline forms.

(iii) The organic crystals act as immersion mode IN.

We believe that organic substances that fulfill these prerequisites have the potential to act as IN and affect the formation of cirrus clouds. In the following, we try to identify organics that meet these criteria. As for criterion (i),

Published by Copernicus GmbH on behalf of the European Geosciences Union. 
several field studies have suggested that dicarboxylic acids are a significant component of the organic fraction with low volatility (Chebbi and Carlier, 1996; Yao et al., 2002). Dicarboxylic acids have been detected in various atmospheric environments, such as the marine boundary layer (Kawamura and Sakaguchi, 1999), at urban sites (Kawamura and Ikushima, 1993), in Arctic aerosols (Narukawa et al., 2003a), in the free troposphere (Narukawa et al., 2003b) and also in biomass burning plumes (Graham et al., 2002). The prevalent dicarboxylic acid is usually oxalic acid, followed by malonic acid and succinic acid. Modelling studies have shown that these acids are formed in aqueous liquid-phase oxidation of organic water soluble substances (Ervens et al., 2004). Oxalic acid is the final sink in the aqueous liquid-phase oxidation scheme, making it the largest single contributor to the organic mass of aqueous aerosols (Ervens et al., 2004).

Criterion (ii) is more restrictive because combined laboratory and modeling studies have revealed that internal mixing of a multitude of solutes - organic and/or inorganic prevents the crystallization of minor components (Marcolli et al., 2004a). One possible exception are several dicarboxylic acids which may form stable crystals with low aqueous solubilities. Marcolli et al. (2004b) identified oxalic, succinic, fumaric, and phthalic acids as possible candidates for organics with a chance to crystallize from multi-component aqueous aerosol particles. It will be shown below that one pathway leading to crystallization of some of these acids is triggered by homogeneous ice formation. Once crystallized, these compounds will remain in crystalline form due to their low solubility even if the ice sublimates subsequently.

Criterion (iii) asks for IN in immersion mode, not in deposition mode. This is justified by considering that dicarboxylic acids are directly emitted into the atmosphere together with other aerosol components and mix internally via gas phase diffusion (Marcolli et al., 2004b). In addition, the smallest dicarboxylic acids are produced by slow conversion of organic precursors in aqueous liquid-phase oxidation reactions in the free troposphere, and, therefore also end up in aerosol particles that consist of a mixture of solutes (Ervens et al., 2004; Legrand et al., 2005). If an organic substance precipitates from a multi-component mixture, its crystals will be embedded in an aqueous solution consisting of inorganic and/or other soluble organic solutes and, therefore, can only act as an immersion IN.

To act in deposition mode, all solutes would have to cocrystallize, which is highly unlikely when considering that many solutes do not crystallize readily such as $\mathrm{H}_{2} \mathrm{SO}_{4}$ or other non-precipitating organics. Aqueous solution aerosol particles consisting of only a single organic component from which a pure organic could crystallize are thermodynamically not favored in the atmosphere. Also the deposition nucleation of organic substances on solid particles are kinetically inhibited as this process requires high supersaturations, however, for water soluble organics high gas phase supersaturations are reduced due to their solubility in aqueous aerosol particles.

While it has been shown that some dicarboxylic acids are inefficient IN in the deposition mode (Prenni et al., 2001; Parsons et al., 2004), their ability to induce ice freezing in the immersion mode is yet unexplored. Therefore, following Marcolli et al. (2004b), this study focusses on oxalic, succinic, adipic, fumaric and phthalic acids, as these have abundance-to-solubility ratios suitable for the formation of solids under atmospheric conditions. The possible role of these five crystalline dicarboxylic acids to act as IN immersed in aqueous solutions have been investigated in differential scanning calorimetry measurements. The obtained results were then implemented in a microphysical box model and in a global climate model to estimate the change in the microphysical properties and the radiative effect of cirrus clouds nucleated heterogeneously compared to exclusively homogeneously formed cirrus clouds.

\section{Experimental section}

\subsection{Experimental setup}

Experiments of emulsified aqueous solutions containing crystalline dicarboxylic acid were performed with a differential scanning calorimeter (DSC, TA Instruments Q10). Measurements were performed with phthalic, adipic, fumaric, succinic and oxalic acid. All substances were obtained from Fluka with purities of $\geq 99 \%$. The emulsions were made by adding a mixture of $23 \mathrm{wt} \%$ lanolin (Fluka Chemical) and $77 \mathrm{wt} \%$ mineral oil (Aldrich Chemical) to the aqueous solutions (made with distilled and deionized water, $18.2 \mathrm{M} \Omega$ ), in which the lanolin/mineral oil represents $80 \%$ of the total volume. The samples were emulsified by applying a commercial drilling machine for $15 \mathrm{~min}$, which leads to a mean diameter of the droplets of $4 \pm 2 \mu \mathrm{m}$. Approximately $30 \pm 5 \mathrm{mg}$ of the emulsions were used for each DSC measurement, containing $\sim 10^{7}$ droplets.

The DSC temperature calibration was performed with the melting point of ice and the ferroelectric phase transition of $\left(\mathrm{NH}_{4}\right)_{2} \mathrm{SO}_{4}$ at $223.1 \mathrm{~K}$. The accuracy of the reported freezing and melting points is $\pm 0.5 \mathrm{~K}$ and $\pm 0.4 \mathrm{~K}$, respectively. Note that the precision of freezing points in a single emulsion is distinctly better than $0.2 \mathrm{~K}$.

\subsection{Experimental procedure}

Figure 1 shows DSC heat flow curves for a typical experimental run with a $4.95 \mathrm{wt} \%$ aqueous oxalic acid solution. First the sample was cooled with a constant cooling rate $\left(10 \mathrm{Kmin}^{-1}\right)$ until the droplets in the emulsion froze (first cycle, solid red line). The onset of the exothermic peak was taken as the freezing point. The sample was then heated up with $1 \mathrm{Kmin}^{-1}$ (solid blue line) to a temperature which we term the conditioning temperature. This temperature was 


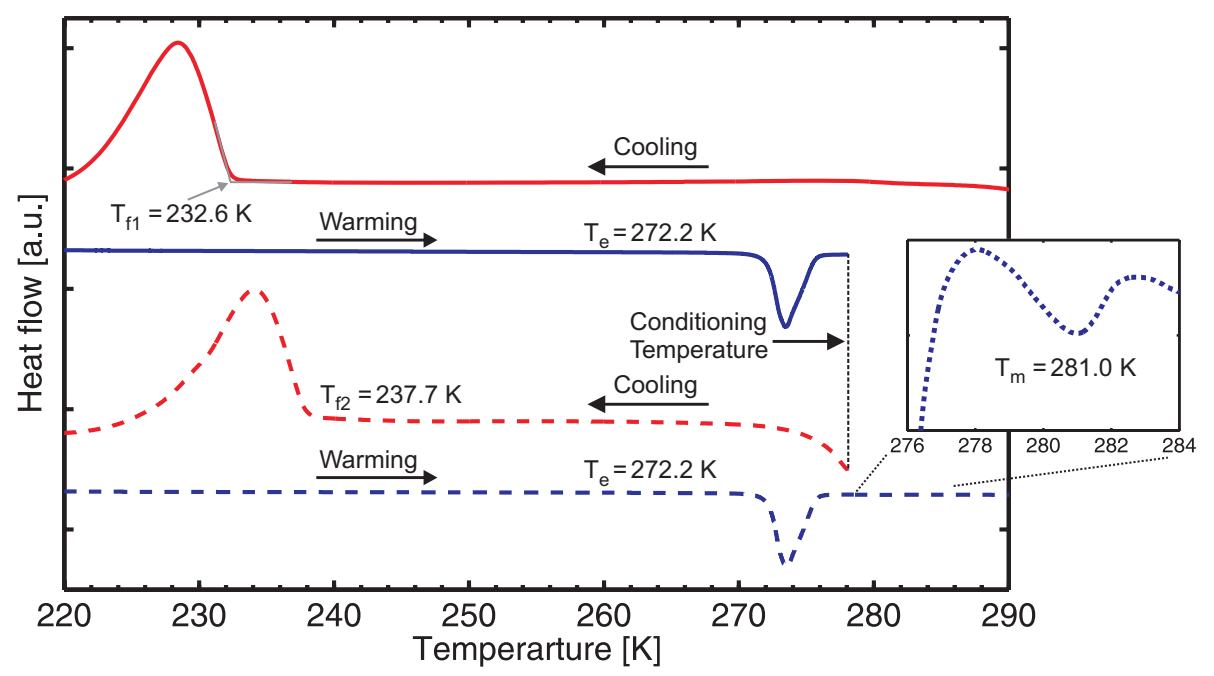

Fig. 1. Typical DSC heat flow experiment of a $4.95 \mathrm{wt} \%$ oxalic acid/water solution. The curves belong to consecutive cooling/heating cycles with the identical sample and are shifted vertically for clarity. Solid red line: first cooling cycle with homogeneous freezing of the oxalic acid solution, i.e., formation of ice and solid oxalic acid. The onset of the heat release, which is given by the intersection of the two thin grey lines, represents the homogeneous ice freezing temperature $\left(T_{\mathrm{f} 1}\right)$. Solid blue line: first heating cycle with an endothermic peak arising from eutectic melting of ice and part of the $\mathrm{OAD}\left(T_{\mathrm{e}}\right)$. The dotted black line is the conditioning temperature at which the sample is stored for $\sim 1$ min in order to ensure complete melting of ice, while some solid oxalic acid crystals remain in the emulsion droplets. Dashed red line: second cooling cycle with $T_{\mathrm{f} 2}$ indicating the heterogeneous ice freezing temperature. Dashed blue line: second heating cycle again showing the eutectic melting $\left(T_{\mathrm{e}}\right)$ again, and an additional melting peak $\left(T_{\mathrm{m}}\right)$ at $281 \mathrm{~K}$ corresponding to the melting of the solid oxalic acid (see insert; note that the $y$-axis of the insert has been enlarged by a factor of 40 ).

chosen to be above the eutectic melting point of ice and oxalic acid, but below the melting point of oxalic acid. The eutectic melting (all of the ice plus a fraction of the oxalic acid) gives rise to the intense peak with an onset at $272.2 \mathrm{~K}$. In a next step, the sample was cooled again with the same cooling rate (second cycle, dashed red line), until freezing occurred. Finally, the sample was heated above the conditioning temperature such that the melting of oxalic acid was also observed (enlarged peak of the dashed blue line). For most of the solutions at least two independently prepared emulsions were investigated and for each emulsion the second freezing cycle was repeated twice.

\section{Results and discussion}

\subsection{Dicarboxylic acid/water systems}

The measurements performed on dicarboxylic acid/water systems are summarized in Table 1. The concentrations of the organic acids have been chosen to cover the atmospherically relevant range and/or to force crystallization of the organic species. The conditioning temperatures were adjusted to ensure that at least part of the dicarboxylic acids remained solid at the end of the first heating cycle. Literature values of the saturation concentrations listed in Table 1 show that the dicarboxylic acids are close to or slightly above saturation at room temperature.
For all but the least concentrated oxalic acid solutions, as well as for the succinic and adipic acid solutions, the freezing of ice occurred in the first cycle at lower temperature than in the second cycle. This temperature difference may be due to two reasons. First, the crystallized dicarboxylic acid acts as a heterogeneous ice nucleus. Second, the concentration of the dicarboxylic acid is reduced to the saturation level in the presence of crystallized dicarboxylic acid leading to a higher homogeneous freezing temperature. The second effect is the more pronounced the higher the initial concentration. Therefore, the second freezing temperature must be actually compared with a reference measurement of a dicarboxylic acid solution that is just saturated at the ice freezing temperature. Since the solubilities of the dicarboxylic acids at around $235 \mathrm{~K}$ are extremely small (e.g., saturation concentration of oxalic acid at $236 \mathrm{~K}$ is around $0.35 \mathrm{wt} \%$, based on a thermodynamical extrapolation of data at higher temperature), pure water was here chosen as the reference (see Table 1). This is a conservative estimate, as the small error induced by this procedure leads to a slight underestimation of the nucleation potential of the organic ice nucleus. In summary, a specific dicarboxylic acid acts as a heterogeneous ice nucleus when the freezing temperature of the second cycle is higher than the homogeneous freezing temperature of pure water. In the following we term this temperature difference $\Delta T_{\text {het }}$.

For all but the least concentrated oxalic acid/water samples, $\Delta T_{\text {het }}$ lies between $1.8-2.0 \mathrm{~K}$, indicating that solid oxalic acid acts as a heterogeneous ice nucleus in the immersion mode. Since no other exothermic peak is found in the 
Table 1. Summary of experiments with binary dicarboxylic acid/water systems and pure water reference measurement. $C_{\text {sample }}$ and $C_{\text {sat }}$ are the sample and the saturation concentration of the specific dicarboxylic acid, respectively. $T_{\mathrm{c}}$ is the conditioning temperature. $T_{\mathrm{f} 1}$ and $T_{\mathrm{f} 2}$ are the freezing temperatures of the first and second cooling cycle, respectively. For most samples these values represent the mean of at least two independent freezing measurements. The largest individual uncertainty in either $T_{\mathrm{f} 1}$ or $T_{\mathrm{f} 2}$ from all measurements is $\pm 0.3 \mathrm{~K}$, but in most experiments it is less than $\pm 0.2 \mathrm{~K} . T_{\mathrm{m}}$ indicates the ice melting point and literature data of melting points are indicated in the brackets.

\begin{tabular}{llllllll}
\hline Solute & $C_{\text {sample }}(\mathrm{wt} \%)$ & $C_{\text {sat }}(\mathrm{wt} \%)$ & $T_{\mathrm{c}}(\mathrm{K})$ & $T_{\mathrm{f} 1}(\mathrm{~K})$ & $T_{\mathrm{m}}{ }^{*}(\mathrm{~K})$ & $T_{\mathrm{f} 2}(\mathrm{~K})$ & $\mathrm{IN}$ \\
\hline pure water & - & - & - & 235.9 & 273.2 & 235.9 & - \\
Oxalic acid & 2.50 & 4.46 at $278.15 \mathrm{~K}^{\dagger}$ & 279 & 234.1 & $272.6\left(272.5^{\&}\right)$ & 234.1 & no \\
Oxalic acid & 4.95 & & 279 & 232.3 & $272.2\left(272.5^{\&}\right)$ & 237.7 & yes \\
Oxalic acid & 9.76 & & 279 & 229.6 & $272.2\left(272.5^{\&}\right)$ & 237.7 & yes \\
Oxalic acid & 19.87 & & 279 & 222.9 & $272.2\left(272.5^{\&}\right)$ & 237.9 & yes \\
Succinic acid & 7.31 & 7.7 at $298 \mathrm{~K}^{\#}$ & 277 & 232.0 & $272.6\left(273.2^{\S}\right)$ & 233.9 & no \\
Adipic acid & 1.61 & 1.4 at $288 \mathrm{~K}^{\#}$ & 279 & 234.6 & $272.6\left(273.2^{\S}\right)$ & 235.1 & no \\
Phthalic acid & 0.63 & 0.54 at $287 \mathrm{~K}^{\#}$ & 279 & 235.5 & 272.6 & 235.6 & no \\
Fumaric acid & 0.50 & 0.499 at $293 \mathrm{~K}^{\#}$ & 279 & 234.9 & 272.6 & 234.9 & no \\
\hline
\end{tabular}

* The melting point is either the eutectic melting point or the ice melting point

$\dagger$ Apelblat and Manzurola (1987), " Stephen and Stephen (1963), \& Braban et al. (2003), § Parsons et al. (2004)

Table 2. Summary of measurements for oxalic acid/aqueous solution systems and for the corresponding reference measurements. The following labels are used for the solutes: oxalic acid (OA), malonic acid (MA), ammonium sulfate (AS), ammonium bisulfate (ABS) and sulfuric acid (SA). The temperature and concentration values are given in Kelvin and weight $\%$ of the total solution, respectively. $T_{\mathrm{f} 1}$ and $T_{\mathrm{f} 2}$ are the freezing temperatures of the first and second cooling cycle, respectively. For most samples these values represent the mean of at least two independent freezing measurements. The largest individual uncertainty in either $T_{\mathrm{f} 1}$ or $T_{\mathrm{f} 2}$ from all measurements is $\pm 0.3 \mathrm{~K}$, but in most experiments it is less than $\pm 0.15 \mathrm{~K}$. $T_{\mathrm{m}}$ indicates the ice melting point of the aqueous solution, with the corresponding literature values in brackets. $\Delta a_{\mathrm{w}, \text { het }}$ values are determined using Eq. (4).

\begin{tabular}{llllllllllll}
\hline \multicolumn{1}{c}{ Measurements of oxalic acid/aqueous solution systems } & \multicolumn{7}{c}{ Reference measurements } \\
\hline Solute & Conc. & OA Conc. & $T_{\mathrm{f} 1}$ & $T_{\mathrm{m}}$ & $T_{\mathrm{f} 2}$ & $\mathrm{IN}$ & Conc. & $T_{\mathrm{f}}$ & $T_{\mathrm{m}}$ & $\Delta T_{\text {het }}$ & $\Delta a_{\mathrm{w}, \text { het }}$ \\
\hline $\mathrm{NaCl}$ & 14.9 & 0.1 & 216.4 & 262.1 & 216.4 & no & 14.9 & $216.9(215.7)^{\dagger}$ & $262.2\left(262.1^{\dagger}\right)$ & -0.5 & - \\
$\mathrm{NaCl}$ & 14.9 & 0.33 & 216.4 & 262.0 & 221.7 & yes & 14.9 & $216.9(215.7)^{\dagger}$ & $262.2\left(262.1^{\dagger}\right)$ & 4.8 & 0.282 \\
$\mathrm{NaCl}$ & 14.9 & 0.5 & 215.9 & 262.0 & 221.3 & yes & 14.9 & $216.9(215.7)^{\dagger}$ & $262.2\left(262.1^{\dagger}\right)$ & 4.4 & 0.284 \\
$\mathrm{MA}$ & 10.0 & 4.0 & 228.4 & 270.5 & 233.5 & yes & 10.7 & 230.5 & $271.2\left(271.3^{\#}\right)$ & 3.0 & 0.288 \\
$\mathrm{MA}$ & 20.0 & 4.0 & 223.1 & 268.2 & 228.9 & yes & 21.4 & 225.0 & $268.8\left(268.9^{\#}\right)$ & 3.9 & 0.284 \\
$\mathrm{MA}$ & 30.0 & 4.0 & 215.2 & 264.8 & 222.1 & yes & 32.1 & 217.8 & $265.5\left(265.2^{\#}\right)$ & 4.3 & 0.284 \\
$\mathrm{MA}$ & 40.0 & 4.0 & 204.2 & 259.7 & 212.9 & yes & 42.8 & 207.9 & $260.1\left(260.9^{\#}\right)$ & 5.0 & 0.284 \\
$\mathrm{AS}$ & 4.0 & 4.0 & 230.3 & 271.8 & 232.3 & no & 4.27 & $232.8(232.3)^{\&}$ & $271.9\left(271.9^{\S}\right)$ & -0.5 & - \\
$\mathrm{AS}$ & 30.0 & 3.0 & 212.1 & 262.8 & 213.2 & no & 31.8 & $210.6(210.7)^{\&}$ & $261.0\left(261.7^{\S}\right)$ & 2.6 & - \\
$\mathrm{ABS}$ & 4.0 & 4.0 & 230.5 & 271.5 & 232.3 & no & 4.27 & $232.0(230.7)^{\mathbb{I}}$ & $271.9\left(271.7^{\S}\right)$ & 0.3 & - \\
$\mathrm{SA}$ & 4.0 & 4.0 & 229.4 & 271.0 & 234.7 & yes & 4.27 & $231.3(231.8)^{\ddagger}$ & $271.4\left(271.3^{\S}\right)$ & 3.4 & 0.285 \\
$\mathrm{SA} / \mathrm{ABS}$ & $2.0 / 2.0$ & 4.0 & 230.0 & 271.2 & 234.6 & yes & $2.13 / 2.13$ & 232.1 & $271.90\left(271.7^{\S}\right)$ & 2.5 & 0.290 \\
\hline
\end{tabular}

${ }^{\dagger}$ Rasmussen and MacKenzie (1972), ${ }^{\#}$ Hansen and Beyer (2004), ${ }^{\&}$ Bertram et al. (2000), ${ }^{\S}$ Clegg et al. (1998), ${ }^{\star}$ Koop et al. (1998), ${ }^{\text {II Koop }}$ et al. (1999)

freezing curves and considering also the melting point in the last heating cycle at $281 \mathrm{~K}$ of Fig. 1, solid oxalic acid must have formed in the first cycle along with or triggered by ice formation. The solid is assumed to precipitate as oxalic acid dihydrate (OAD) nano-crystals (Braban et al., 2003). Heterogeneous nucleation was not observed for the $2.5 \mathrm{wt} \%$ aque- ous oxalic acid solution since it is below the eutectic concentration of $\sim 3 \mathrm{wt} \%$, and hence no solid compounds remained in the droplets after the first heating cycle. Therefore the freezing temperatures of both cycles are identical and the measured endothermic peak does not indicate eutectic but regular ice melting. Melting points and eutectic 
points of these solutions are in good agreement with Braban et al. (2003), who investigated aerosol phase transitions (deliquescence and efflorescence) and bulk solution properties of these aqueous solutions, but not their ice nucleation potential. The concentration of oxalic acid in the solutions, and hence the surface area of the solid OAD, are varied over a considerable range: assuming a single spherical nucleus, the surface of OAD of the most concentrated solution is larger by a factor of 2.4 than in the $5 \mathrm{wt} \%$ solution. Nevertheless, the heterogeneous freezing temperatures differ by only $\sim 0.2 \mathrm{~K}$, which is less than the variability caused by different emulsions. From this we conclude that the heterogeneous freezing rate coefficient under these conditions must be a very steep function of temperature, which is not unusual for ice nucleation processes (Pruppacher and Klett, 1997).

In a similar study with solid $\left(\mathrm{NH}_{4}\right)_{2} \mathrm{SO}_{4}$ as a heterogeneous ice nucleus, Zuberi et al. (2001) have found that heterogeneous freezing temperature of ice on ammonium sulfate crystals occurred at warmer temperatures if the conditioning temperature was closer to the $\left(\mathrm{NH}_{4}\right)_{2} \mathrm{SO}_{4}-\mathrm{H}_{2} \mathrm{O}$ eutectic temperature. The authors concluded that the surface area and surface microstructure of the $\left(\mathrm{NH}_{4}\right)_{2} \mathrm{SO}_{4}$ crystals changed with different conditioning temperatures, leading to a change in the heterogeneous freezing temperature. We have performed similar heterogeneous freezing experiments with a $4.95 \mathrm{wt} \%$ and a $9.76 \mathrm{wt} \%$ oxalic acid solution by varying the conditioning temperature over a range of $277-283 \mathrm{~K}$ and $279-293 \mathrm{~K}$, respectively. When the conditioning temperature for the $4.95 \mathrm{wt} \%$ and the $9.86 \mathrm{wt} \%$ oxalic acid solution was above $\mathrm{T} \geq 281 \mathrm{~K}$ and $\mathrm{T} \geq 291 \mathrm{~K}$, respectively, heterogeneous ice nucleation was no longer observed, i.e., a complete melting of the oxalic acid dihydrate crystals had occurred (equivalent to the case of a $2.5 \mathrm{wt} \%$ oxalic acid solution in the first row in Table 1). For all other conditioning temperatures we did not observe any change in the heterogeneous ice freezing temperature, indicating that the crystal microstructure is probably unimportant for heterogeneous ice nucleation on OAD nano-crystals.

The freezing points of the second cycles of the other dicarboxylic acids are all lower than the reference measurement with pure water, indicating that heterogeneous nucleation is inefficient and that freezing point depression due to higher solution concentration dominates. Two cases can be distinguished. First, succinic and adipic acid show a similar behavior as oxalic acid with a clear temperature difference between the first and second cooling cycles. Hence, succinic and adipic acid must have crystallized, although their melting points could not be detected when the samples were heated above the conditioning temperature at the end of the experiment. In a recent study, Parsons et al. (2004) concluded that succinic and adipic acid are not good IN above $243 \mathrm{~K}$ in the ice deposition mode. From both data sets, we conclude that these solid acids are unlikely to play any role in heterogeneous ice nucleation in the atmosphere, neither in deposition nor in immersion mode. In the case of phthalic and fumaric acid, the difference of the freezing temperatures between the two cycles are negligibly small because of the low initial concentrations, but since both acids are supersaturated substantially during ice formation, we may nevertheless assume that the acids have crystallized. With the chosen concentrations these nuclei would not melt at the conditioning temperature. Hence, phthalic and fumaric acid are also unlikely to act as IN under atmospheric conditions.

In summary, our results show that out of these five candidates only solid oxalic acid serves as an ice nucleus. However, under atmospheric conditions, solid oxalic acid IN will rarely occur in pure water, but in aqueous solutions together with other organic or inorganic species. Such mixed systems are discussed in the next section.

\subsection{Oxalic acid/aqueous solutions systems}

For the oxalic acid/aqueous solution systems the same experimental procedure was used as for the pure dicarboxylic acid solutions with suitable choices for reference samples. Measurements were performed with different inorganic and organic aqueous solutions, all containing various amounts of oxalic acid (Table 2). The exact composition of the solutions in equilibrium with OAD is not generally known. This problem can be overcome by distinguishing two cases. If the concentration of the oxalic acid is negligibly small compared to the additional solute, the concentration of the reference sample can be taken as composition of the initial solution without the oxalic acid. (e.g. solution of interest: $14.9 \mathrm{wt} \% \mathrm{NaCl} /$ $0.5 \mathrm{wt} \%$ oxalic acid, reference solution: $14.9 \mathrm{wt} \% \mathrm{NaCl}$ ). However, if oxalic acid constitutes a substantial part of the total solute, a considerable error would be introduced by the above procedure. After the crystallization of the OAD in the first cycle, most of the oxalic acid and a minor part of the water are withdrawn from the solution. Consequently, the sample is more concentrated with respect to the additional solute. Therefore the concentration of the reference sample was adjusted for each investigated solution assuming that upon crystallization of OAD no oxalic acid is left in the solution (e.g. solution of interest: $40.0 \mathrm{wt} \%$ Malonic acid/4 wt $\%$ oxalic acid, reference solution: $42.7 \mathrm{wt} \%$ Malonic acid).

\subsubsection{Aqueous $\mathrm{NaCl} /$ oxalic acid}

The solubility of oxalic acid is drastically decreased in a highly concentrated $\mathrm{NaCl}$ solution. While the solution with $0.1 \mathrm{wt} \%$ oxalic acid is subsaturated at room temperature, those with 0.33 and $0.5 \mathrm{wt} \%$ oxalic acid are supersaturated. Consequently these two solutions had to be placed in a water bath $(\sim 310 \mathrm{~K})$ before the emulsions could be prepared. The freezing temperatures of the first and the second cycles are identical for the weakest concentrated solution and thus no solid oxalic acid exists in the droplets after the first heating cycle. The other two solutions show the same behavior as the binary oxalic acid/water system. Namely, the freezing 

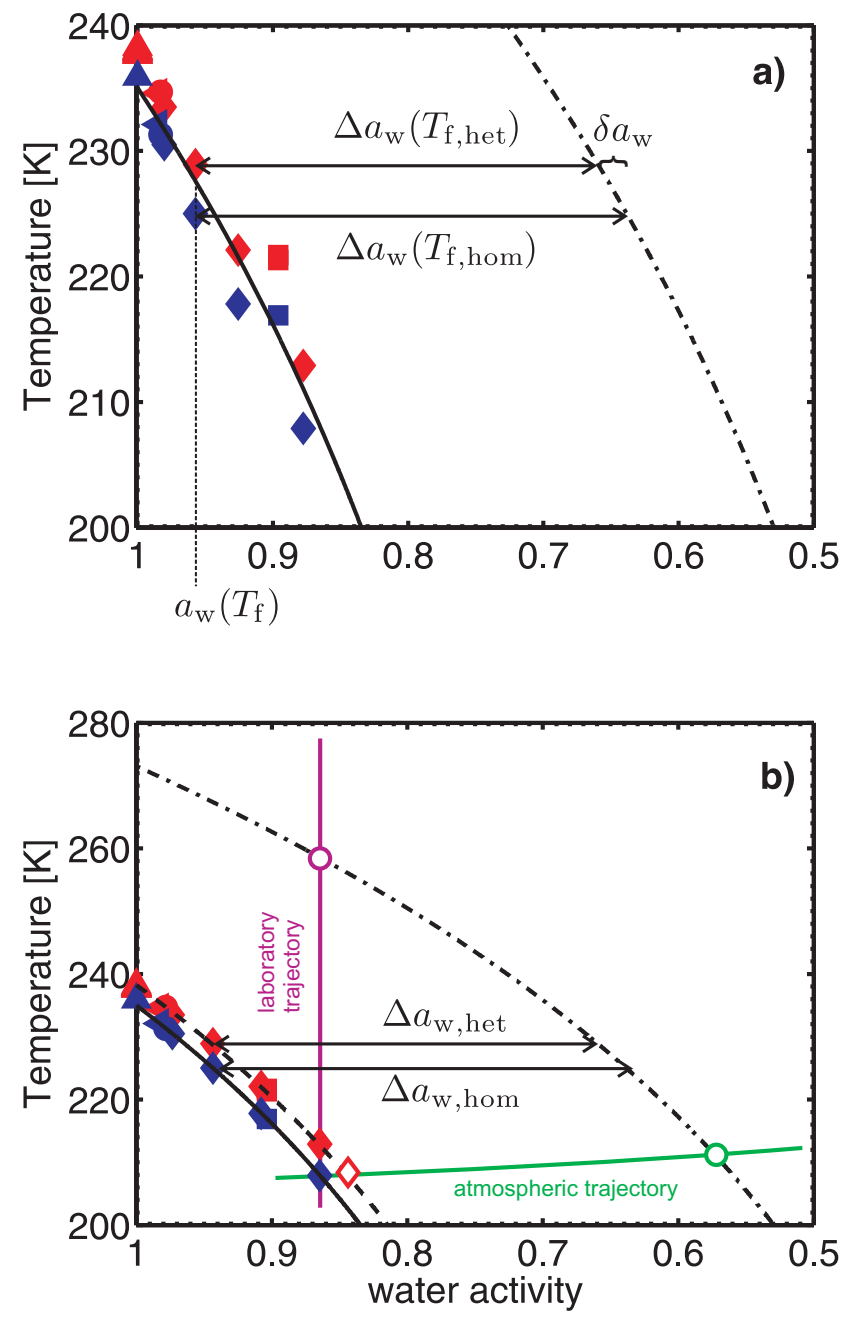

Fig. 2. Experimental freezing points of micrometer sized aqueous solution droplets. (a) Heterogeneous ice freezing points in the presence of OAD nano-crystals (red symbols) and homogeneous ice freezing points (reference, blue symbols) as a function of water activity. Upward triangles: water; left pointing triangles: SA/ABS; bullets: SA; diamonds: MA; squares: $\mathrm{NaCl}$ (see Table 2). Red and blue symbols appear as pairs at given water activity indicating the ice freezing temperatures of a specific solution in the presence or absence of OAD IN. The solid line is the homogeneous ice freezing curve for supercooled aqueous solutions and the dash-dotted line is the ice melting point curve (Koop et al., 2000). (b) Lines and symbols as in (a). The various pairs of freezing points were shifted horizontally such that the homogeneous freezing point of the reference sample is in accordance with the homogeneous freezing point line (solid). The magenta and green lines indicate a typical laboratory DSC trajectory and an atmospheric trajectory with ice melting points shown by the magenta and green circles, respectively. Under atmospheric conditions, aerosol particles containing OAD nanocrystals will nucleate ice heterogeneously at a lower water activity, and thus lower supersaturation (open red diamond) than is required for homogeneous ice nucleation without OAD (blue diamond). points of the second cycle are clearly higher $\left(\Delta T_{\text {het }} \sim 4.5 \mathrm{~K}\right)$ than that of the reference measurement with a $14.9 \mathrm{wt} \% \mathrm{NaCl}$ solution. Again, $\Delta T_{\text {het }}$ does not depend on the oxalic acid concentration. The melting peak of the solid oxalic acid is smaller than the resolution of the DSC and could not be observed at the end of the experiment.

\subsubsection{Aqueous malonic acid/oxalic acid}

For the malonic/oxalic acid solutions, the concentrations of malonic acid are varied from $10 \mathrm{wt} \%$ to $40 \mathrm{wt} \%$, whereas the oxalic acid concentration was held constant at $4 \mathrm{wt} \%$. None of these solutions are supersaturated at room temperature. Heterogenous ice nucleation induced by OAD is observed in all experiments. $\Delta T_{\text {het }}$ varied between 3.0 and $5.0 \mathrm{~K}$. The melting of the solid oxalic acid has been identified in all measurements, whereby the melting temperatures increase with increasing concentration of the malonic acid, indicating that the presence of malonic acid decreases the solubility of oxalic acid in the sample.

\subsubsection{Aqueous $\left(\mathrm{NH}_{4}\right)_{2} \mathrm{SO}_{4}$ /oxalic acid and $\mathrm{NH}_{4} \mathrm{HSO}_{4}$ /oxalic acid}

In the presence of $\left(\mathrm{NH}_{4}\right)_{2} \mathrm{SO}_{4}$ (AS) and $\mathrm{NH}_{4} \mathrm{HSO}_{4}(\mathrm{ABS})$ the solubility of oxalic acid is strongly reduced. The stock solution had to be put in a hot water bath for full dissolution. When the solutions were kept at room temperature overnight, crystals slowly formed again. Nevertheless, the temperature difference between the first and the second freezing cycle are in accordance with a homogeneous freezing process. $\Delta T_{\text {het }}$ is approximately zero for the $4 \mathrm{wt} \% / 4 \mathrm{wt} \%$ AS/oxalic acid and the $4 \mathrm{wt} \% / 4 \mathrm{wt} \%$ ABS/oxalic acid systems. The positive value for the $30 \mathrm{wt} \% / 3 \mathrm{wt} \%$ AS/oxalic acid solution cannot be considered as an indication of heterogeneous freezing since the melting point is also elevated by $1.5 \mathrm{~K}$ compared with the reference measurement. Nevertheless a solid phase must have formed based on the increase in the freezing temperature between the first and the second freezing cycle and the elevated melting temperature. This solid phase is not active as a heterogeneous ice nucleus, and therefore must be different from OAD. To confirm this hypothesis we determined the composition of the crystals that crystallized from the stock solution by elemental analysis $(\mathrm{C}, \mathrm{H}, \mathrm{N}, \mathrm{S}, \mathrm{O}$ by pyrolysis method and $\mathrm{H}_{2} \mathrm{O}$ by Karl Fischer, Solvias AG Basel Switzerland). The absence of sulfur and the relative ratio of the other elements indicates that this new phase consists of ammonium, oxalic acid and water in a ratio of 1:2:2. This stoichiometry is in agreement with the formation of $\mathrm{NH}_{4} \mathrm{H}_{3}\left(\mathrm{C}_{2} \mathrm{O}_{4}\right)_{2} \times 2 \mathrm{H}_{2} \mathrm{O}$, a precipitate that was also reported to form in ammoniated oxalic acid solutions above room temperature (Stephen and Stephen, 1964). We conclude that oxalic acid precipitated as $\mathrm{NH}_{4} \mathrm{H}_{3}\left(\mathrm{C}_{2} \mathrm{O}_{4}\right)_{2} \times 2 \mathrm{H}_{2} \mathrm{O}$ in the experiments, indicating that it is not oxalic acid per se that acts as an IN, but rather only its dihydrate. 

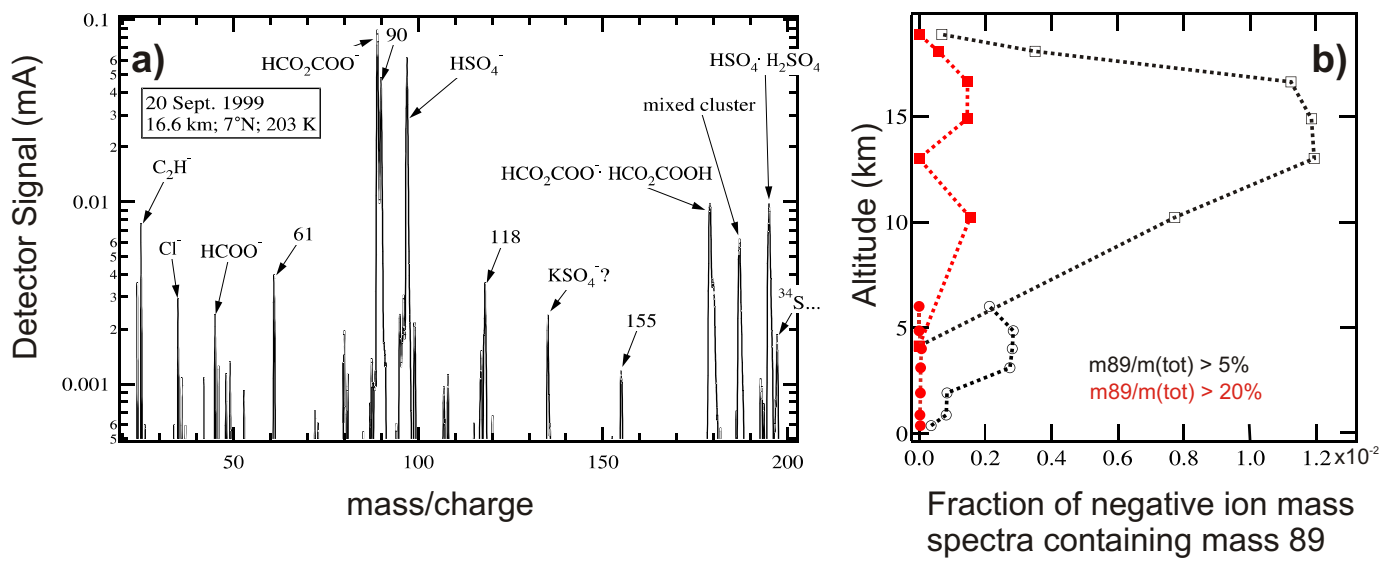

Fig. 3. (a) Mass spectra of the PALMS with a large mass peak 89. (b) The frequency of negative ion mass spectra measured by the PALMS instrument, where the relative intensity of the m89 peak is 5\% (black) or 20\% (red) of the total ion signal. The B57 (open and solid squares; 33323 spectra, mostly above $10 \mathrm{~km}$ ) data include flights from 1998 (WAM), 1999 (ACCENT) and 2004 (PAVE) missions. The P3 data (open and solid circles; 249.949 spectra, below $7 \mathrm{~km}$ ) are from 2004 (NEAQS/ICARTT).

\subsubsection{Aqueous $\mathrm{H}_{2} \mathrm{SO}_{4}$ /oxalic acid and $\mathrm{H}_{2} \mathrm{SO}_{4} / \mathrm{NH}_{4} \mathrm{HSO}_{4} /$ oxalic acid}

investigated OAD-induced ice nucleation in acidic solutions with sulfuric acid (SA) and a mixture of SA and ABS. We found no evidence of any deterioration of the emulsions. The $\Delta T_{\text {het }}$ values clearly show that heterogeneous nucleation occurred. Therefore OAD must have crystallized under these acidic conditions.

3.3 Water-activity-based theory for heterogeneous ice nucleation

It has been shown that homogeneous ice nucleation in aqueous solutions depends solely on the water activity of the solution independently of the nature of the solute (Koop et al., 2000). Therefore, a water activity dependence of heterogeneous immersion freezing of ice is well conceivable. In fact, experimental studies with inorganic nuclei seem to support this view (Zuberi et al., 2002; Archuleta et al., 2005), and a water-activity-based parameterization of heterogeneous freezing for model applications has been proposed (Kärcher and Lohmann, 2003). In Fig. 2a heterogeneous freezing points of droplets with immersed OAD nanocrystals and reference measurements without OAD nanocrystals are shown as a function of the solution water activity, $a_{\mathrm{w}}$. The $a_{\mathrm{w}}$-values of the reference solutions were determined from the measured ice melting point temperatures, $T_{\mathrm{m}}$. In order to estimate $a_{\mathrm{w}}$ at the freezing temperatures it was assumed that $a_{\mathrm{w}}$ in these solutions does not depend on temperature, i.e., $a_{\mathrm{w}}\left(T_{\mathrm{f}}\right) \approx a_{\mathrm{w}}\left(T_{\mathrm{m}}\right)$. In addition, since the solubility of OAD at the heterogeneous freezing point is extremely small, the $a_{\mathrm{w}}$-values determined in the reference measurements were also adopted for the solutions containing OAD nano-crystals.
In previous studies (Koop et al., 2000), it was found that the homogeneous ice freezing points of a large number of aqueous solutions scatter around a common homogeneous freezing point line (solid line) that is horizontally parallel to the ice melting point line (dash-dotted line), i.e., a constant offset between the two lines exists. More generally, a horizontal offset with respect to the ice melting point curve can be determined for any individual heterogeneous freezing point, $\Delta a_{\mathrm{w}}\left(T_{\mathrm{f}, \text { het }}\right)$, and homogeneous freezing point, $\Delta a_{\mathrm{w}}\left(T_{\mathrm{f}, \text { hom }}\right)$, by evaluating:

$\Delta a_{\mathrm{w}}\left(T_{\mathrm{f}, \text { het }}\right)=a_{\mathrm{w}}\left(T_{\mathrm{f}}\right)-a_{\mathrm{w}}^{\mathrm{i}}\left(T_{\mathrm{f}, \text { het }}\right)$

and

$\Delta a_{\mathrm{w}}\left(T_{\mathrm{f}, \text { hom }}\right)=a_{\mathrm{w}}\left(T_{\mathrm{f}}\right)-a_{\mathrm{w}}^{\mathrm{i}}\left(T_{\mathrm{f}, \text { hom }}\right)$

where $a_{\mathrm{w}}\left(T_{\mathrm{f}}\right) \approx a_{\mathrm{w}}\left(T_{\mathrm{m}}\right)$ is the water activity at the freezing point determined from the measured ice melting point, and $a_{\mathrm{w}}^{\mathrm{i}}\left(T_{\mathrm{f}, \text { het }}\right)$ and $a_{\mathrm{w}}^{\mathrm{i}}\left(T_{\mathrm{f}, \text { hom }}\right)$ are the water activities on the ice melting point curve at the heterogeneous and homogeneous freezing temperature, respectively. Subtracting Eq. 1 from Eq. 2 defines the corresponding difference in water activity, $\delta a_{\mathrm{w}}$, between each pair of heterogeneous/homogeneous ice freezing points corresponding to a sample-with-OAD/reference-without-OAD pair:

$\delta a_{\mathrm{w}}=\Delta a_{\mathrm{w}}\left(T_{\mathrm{f}, \text { hom }}\right)-\Delta a_{\mathrm{w}}\left(T_{\mathrm{f}, \text { het }}\right)$.

This $\delta a_{\mathrm{w}}$ is indicated in Fig. 2a for one sample/reference pair and was used to evaluate the raw data.

We note, that the homogeneous freezing points (blue) scatter - by less than $2 \%$ in $a_{\mathrm{w}}$ - around the homogeneous ice freezing line predicted by water-activity-based ice nucleation theory (black line). The most likely explanation for these small differences is that the water activity in the investigated solutions changes slightly with temperature, and is not constant 
as was assumed to construct Fig. 2a. Such small changes in water activity with decreasing temperature are quite common, however, measurements of $a_{\mathrm{w}}$ in solutions supersaturated with respect to ice are not available for the investigated solutions at low temperatures. Recently, Braban et al. (2003) measured the water activity of malonic acid solutions in bulk samples as a function of temperature, however, only above $274 \mathrm{~K}$. Their data, together with measurements at room temperature of Choi and Chan (2002), indicate that within experimental error no temperature dependence of the water activity of malonic acid above the ice melting point exists for concentrations relevant to our study. However, it is known from other organic substances that the water activity may indeed vary strongly with decreasing temperature (Zobrist et al., 2003; Koop, 2004).

In order to assess the effect of OAD crystals on heterogeneous ice nucleation in terms of $a_{\mathrm{w}}$, we provide another perspective of the experimental data in Fig. 2b. To remove the scatter in the data stemming from the uncertainties in $a_{\mathrm{w}}\left(T_{\mathrm{f}}\right)$, we adjusted $a_{\mathrm{w}}\left(T_{\mathrm{f}}\right)$ such that all measured homogeneous freezing points fall onto the water-activity-based homogeneous freezing line. Technically this can be achieved by defining a $\Delta a_{\mathrm{w}, \text { het }}$ which can be calculated for each measured heterogeneous freezing point by:

$\Delta a_{\mathrm{w}, \text { het }}=\Delta a_{\mathrm{w}, \mathrm{hom}}-\delta a_{\mathrm{w}}$

where $\Delta a_{\mathrm{w}, \mathrm{hom}}=0.305$ (Koop et al., 2000) and $\delta a_{\mathrm{w}}$ was taken from the evaluation of the raw data, as discussed above. The results of this procedure are shown in Fig. $2 \mathrm{~b}$ with the individual $\Delta a_{\mathrm{w}}$,het-values for each sample given in Table 2 . The arithmetic mean of all measurements yields a value of $\Delta a_{\mathrm{w}, \text { het }}=0.285$ with a standard deviation of $2.6 \times 10^{-3}$. The very small scatter in the heterogeneous freezing data around the dashed line corresponding to $\Delta a_{\mathrm{w}, \text { het }}=0.285$ as well as the very small standard deviation in $\Delta a_{\mathrm{w}}$,het provides strong support for a treatment of immersion freezing within the framework of water-activity-based nucleation theory, see Appendix B.

It should be noted that atmospheric aerosol particles in a cooling air parcel follow a pathway different from that used in our experiments. In the laboratory, the droplets are cooled at a constant composition until they freeze homogeneously or heterogeneously. The laboratory trajectory for a solution containing $40 \mathrm{wt} \%$ malonic acid and $4 \mathrm{wt} \%$ oxalic acid is shown schematically as the magenta line in Fig. $2 b$. In contrast, the composition of an atmospheric aerosol droplet is determined from the balance of water partial and vapor pressures (green line), i.e., from relative humidity, which is equal to $a_{\mathrm{w}}$ under equilibrium conditions. Once the atmospheric trajectory has passed the frost point (green circle), the aerosol particles are supersaturated with respect to ice. Liquid droplets will freeze at the homogeneous freezing point (blue diamond), unless they contain an ice nucleus such as an OAD nano-crystal which will induce freezing when they reach the heterogeneous freezing line (open red diamond). So far it was shown that oxalic acid may act as a immersion mode ice nucleus and that the effect of OAD on freezing temperature can be parameterized using water activity. In Appendix B, we use this information to estimate the heterogeneous ice nucleation rate coefficient for immersion nucleation and how it can be parameterized for inclusion into a microphysical box model. In the following section, the occurrence of OAD in the UT and its possible influence on the microphysical and radiative properties of cirrus clouds are investigated.

\section{Atmospheric implications}

\subsection{Single particle measurements}

In a recent field campaign in the UT, oxalic acid constituted a considerable fraction of the total classified organics (Narukawa et al., 2003b). The presence of oxalic acid in upper tropospheric aerosols is also supported by particle analysis by laser mass spectrometry (PALMS) instrument. Figure 3a shows an example of a PALMS single particle mass spectrum that contains an oxalate peak at mass peak 89 . The cluster ions at mass peak 179 show that the mass peak 89 is due to a molecule with a mass of 90 which readily loses a proton and undergoes little fragmentation. The lack of major isotopes eliminates any molecules with sulfur, chlorine, etc. Oxalic acid is the only species identified in aerosol particles with these characteristics, although peroxypropionic acid and hydroxypropionic acid have the same molecular weight. This exemplary particle is probably quite acidic because laboratory tests have shown that cluster ions containing $\mathrm{H}_{2} \mathrm{SO}_{4}$ are more common in mass spectra from sulfuric acid than from ammonium sulfate. Up to $1 \%$ of the total mass spectra collected in several field campaigns contained a significant oxalate ion peak.

Figure $3 \mathrm{~b}$ depicts a vertical distribution of the mass peak 89 , indicating a clear maximum of oxalate in the mass spectra in the middle and upper troposphere. At lower altitudes, besides a lower abundance of mass 89 in the spectra, those particles showing mass 89 were usually neutralized (as indicated by the simultaneous presence of sulfate, nitrate, and a wide variety of organic acid peaks) instead of acidic as in the example in Fig. 3a. The frequency of the oxalic acid enriched particles starts to fall off also in the stratosphere with the smaller overall proportion of organic material there (Murphy et al., 1998).

PALMS was flown in the CRYSTAL-FACE campaign in 2002 with a counterflow virtual impactor inlet with the capability of separating ice crystals from interstitial aerosol particles and then evaporating the water by heating the inlet to detect the ice nucleus (Cziczo et al., 2004b). Despite the heating, one of the mass spectra of ice nuclei had a significant oxalate peak as well as sulfate probably in the 


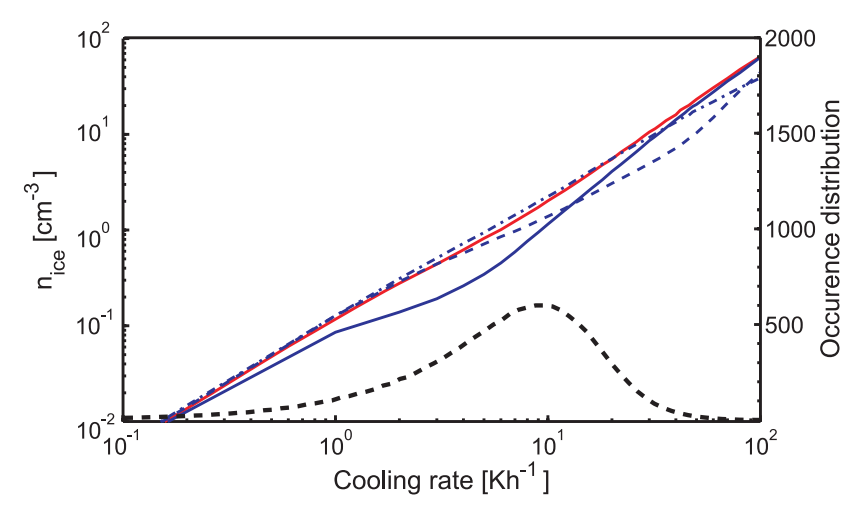

Fig. 4. Ice number density as a function of cooling rates for homogeneous and heterogeneous ice nucleation with OAD. Colored curves: simulated ice number density as a function of cooling rate. Red line: only homogeneous nucleation. Blue lines: homogeneous nucleation together with heterogeneous nucleation on solid oxalic acid aerosols with various IN numbers for oxalic acid. Solid, dashed and dashed dotted blue line: $\mathrm{n}_{\mathrm{OAD}}=0.1,1$ and $10 \mathrm{~cm}^{-3}$, respectively. Black dashed line: occurrence distribution of mesoscale cooling rates based on aircraft measurement during the SUCCESS campaign (see Appendix B and Hoyle et al., 2005).

form of sulfuric acid (199 ice crystals were sampled in this flight). Although only one particle, it does indicate that mixed particles of oxalic and sulfuric acid can act as ice nuclei in clouds. This spectrum of an ice nucleus had the largest oxalate peak of any particle observed during the CRYSTAL-FACE mission and was acquired at $14.4 \mathrm{~km}$ altitude during a flight on the 9 July 2002 south along the Yucatan peninsula (Cziczo et al., 2004b). It is interesting to note that most of the cirrus clouds sampled during this mission were convectively formed and contained residues with the signature of aerosols of boundary layer and lower tropospheric origin (e.g., sea salt and mineral dust). The cloud encountered on the 9 July was the only case of a cloud which appeared to freeze from aerosols with a free tropospheric signature (i.e., predominantly sulfates).

The OAD nano-crystal precipitation in the atmosphere may be triggered by ice formation when a cirrus cloud is nucleated homogeneously, similar to the laboratory experiments. Once formed, OAD nano-crystals will grow via gas phase diffusion of oxalic acid at the expense of remaining liquid particles, similar to a Bergeron-Findeisen process. Vapor pressure measurements of aqueous oxalic acid particles performed in an electrodynamic balance (see Appendix A) suggest that the growth of a OAD nano-crystal to a particle with a radius of $0.1 \mu \mathrm{m}$ takes $33 \mathrm{~h}$ at $235 \mathrm{~K}$, which is sufficiently fast to occur on atmospheric time scales. Because of their low solubility and vapor pressure OAD nano-crystals will persist even if the ice crystals sublimate in drier air masses or at lower altitudes in sedimenting ice particles.

\subsection{Microphysical Box model}

In order to investigate the change in the microphysical properties of cirrus clouds nucleated on OAD compared to cirrus clouds exclusively formed by homogeneous nucleation, the microphysical box model first described by Hoyle et al. (2005) was expanded to include heterogeneous ice nucleation (see Appendix B). Figure 4 shows the simulated ice number densities $\left(n_{\text {ice }}\right)$ as a function of constant cooling rate in the absence and presence of OAD nano-crystals. The presence of a limited number of heterogeneous IN reduces the final ice number density largely when compared to the homogeneous case, an effect that has also been observed in a similar modeling study (Kärcher and Lohmann, 2003). For a given IN number density, the reduction in $n_{\text {ice }}$ when compared to homogeneous nucleation is largest at cooling rates greater than that cooling rate, at which $n_{\text {ice,hom }}$ is approximately equal to IN number density.

Occurrence frequencies of ice particle number densities $\left(n_{\text {ice }}\right)$ can be simulated for initial homogeneous nucleation followed by competitive OAD-induced heterogeneous and homogeneous ice nucleation. The simulations were performed at temperatures of 200,215 and $230 \mathrm{~K}$ thus covering a range in altitudes from $11-15 \mathrm{~km}$. The results shown in Fig. 5 indicate that the presence of OAD in the aerosols leads to a reduction in $n_{\text {ice }}$ by up to $\sim 50 \%$ when compared to purely homogeneous freezing, resulting in $\sim 20 \%$ decrease in optical depth, which corresponds to a negative Twomey effect (Kärcher and Lohmann, 2003; Lohmann and Feichter, 2005). In addition, fewer ice particles with larger sizes sediment faster and reduce the lifetime of the cloud.

\subsection{Global radiative modeling}

We calculated the shortwave and longwave radiative effect at the top-of-the atmosphere (TOA) using the ECHAM4 climate model (Appendix $C$ ) in order to investigate the global impact of the reduction of $n_{\text {ice }}$ caused by heterogeneous freezing in the presence of OAD compared to cirrus clouds exclusively formed by homogeneous nucleation. This effect was obtained by implementing the temperature dependent increase in effective ice crystal radius in the radiation routine derived from the above microphysical calculations (see Fig. 5). The radiative transfer scheme was then called once again diagnostically with this changed effective radius while keeping all other parameters the same, such as ice water content and cloud cover. Figure 6 shows shortwave and longwave TOA effect of cirrus clouds formed in the presence of OAD nano-crystals compared to cirrus clouds exclusively homogeneously nucleated.

With the obtained temperature dependent reduction of $n_{\text {ice }}$, heterogeneous freezing in the presence of OAD causes a global mean negative Twomey effect of $+0.3 \mathrm{Wm}^{-2}$ in the shortwave that is overcompensated by increased longwave emission of $-0.6 \mathrm{Wm}^{-2}$, yielding a net effect of 


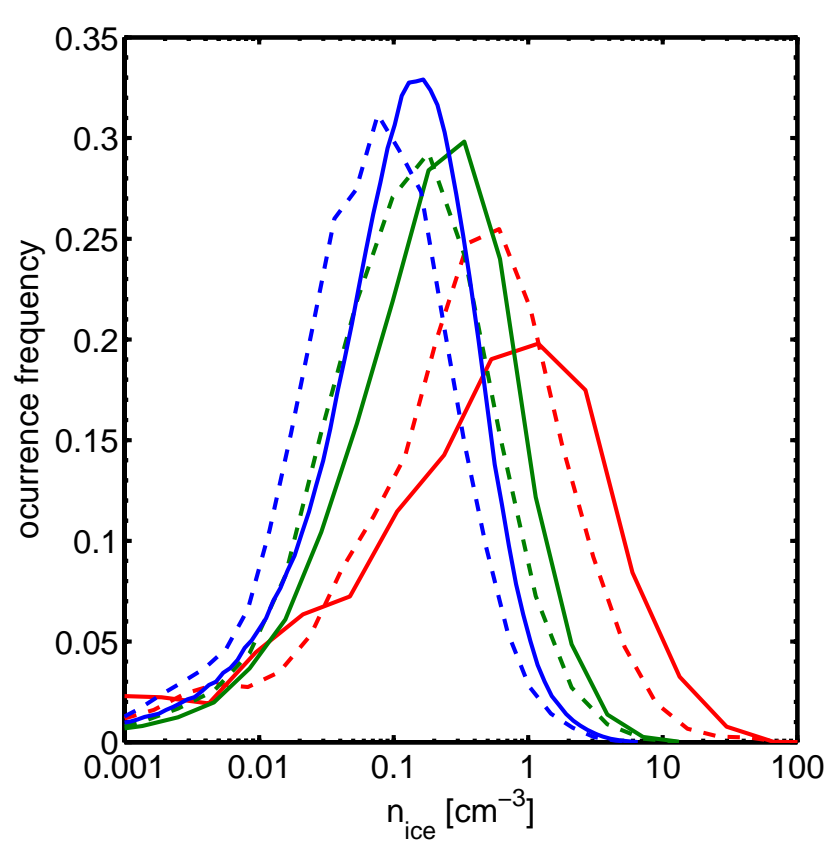

Fig. 5. Simulated ice particle number density distribution of cirrus clouds on three different height levels induced by homogeneous ice nucleation alone (solid lines) and by homogeneous together with heterogeneous ice nucleation on OAD particles (dashed lines). red: $15 \mathrm{~km}, \mathrm{~T}=200 \mathrm{~K}$, ice water content (IWC) $=6 \mathrm{ppm}$; green: $13 \mathrm{~km}$, $\mathrm{T}=215 \mathrm{~K}, \mathrm{IWC}=38 \mathrm{ppm}$; blue: $11 \mathrm{~km}, \mathrm{~T}=230 \mathrm{~K}, \mathrm{IWC}=180 \mathrm{ppm}$.

$-0.3 \mathrm{Wm}^{-2}$. This effect is most pronounced in areas of tropical deep convection and extratropical storm tracks. This estimate represents an upper bound because all cirrus clouds were considered to have frozen in the presence of OAD.

These results pose the question, which fraction of atmospheric ice particles might actually nucleate in the absence of OAD, which would then reduce the estimate in Fig.6? We have presently no suitable method to estimate which percentage of all cirrus clouds in the real atmosphere has previously undergone ice formation, exposing them to the effect of OAD, and which percentage of all cirrus clouds has nucleated for the first time, i.e., without exposure to OAD. This percentage might be different for regions with cirrus originating predominantly from deep convection than for regions with cirrus nucleating predominantly in situ in slow upwelling. For liquid clouds it is well known that the water undergoes multiple condensation and evaporation cycles before the water precipitates, typically 10-times (Pruppacher and Jaenicke, 1995). Although it is likely to be similar for ice clouds, we are not aware of investigations of this issue.

We have attempted to estimate how many freezing/evaporation cycles an air mass passes through by using trajectory calculations based on the 3-dimensional, 6 hourly wind fields of the 40 year reanalysis ERA-40 provided by the European Centre for Medium-range Weather Forecast (ECMWF). 10-day backward trajectories provide
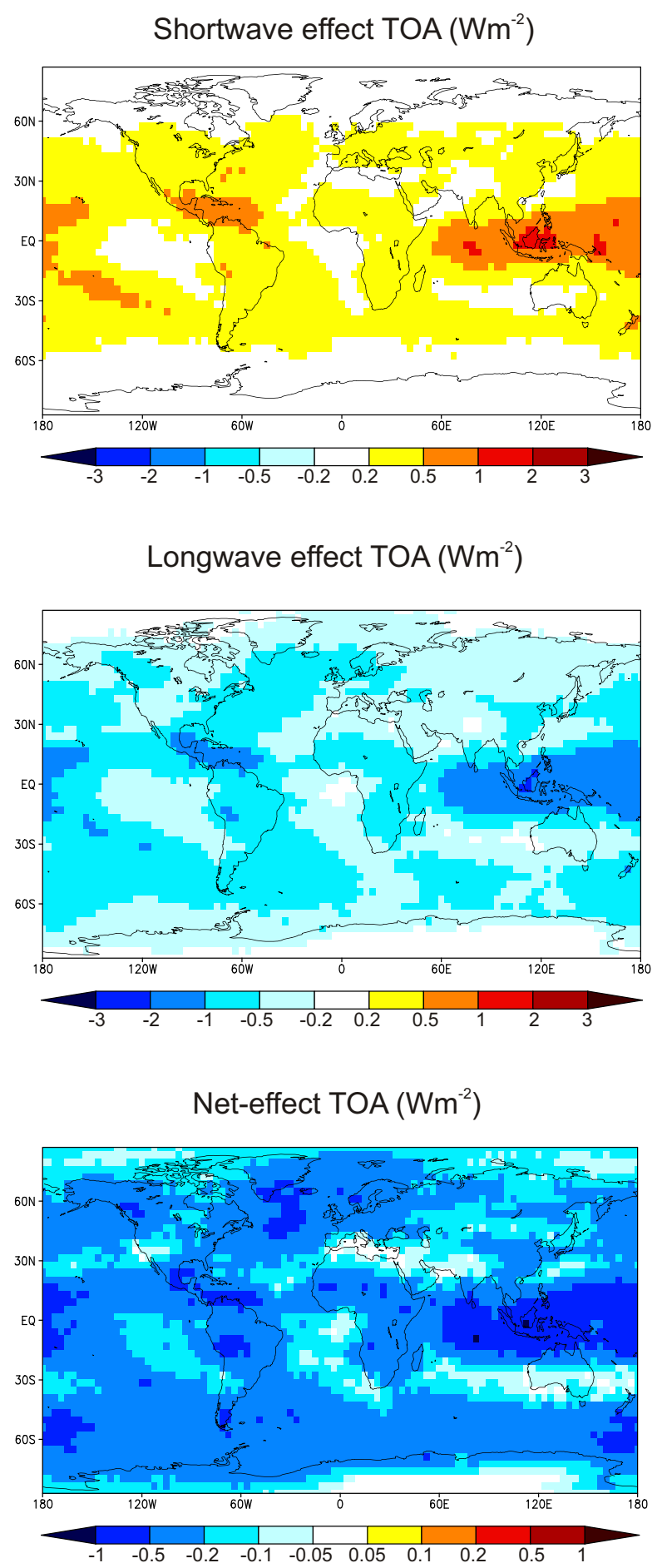

Fig. 6. Global shortwave, longwave and net TOA effect of cirrus clouds that have nucleated heterogeneously on solid OAD particles as compared to cirrus clouds formed in the absence of OAD. A positive shortwave effect means that less solar radiation is reflected to space. A negative longwave effect means that more longwave radiation is emitted to space. 
the required information to determine the fraction of clouds nucleating in air parcels that had previously been glaciated and therefore contain OAD. It was found that at $150 \mathrm{hPa}$ typically $90 \%$ of all air in cirrus clouds had experienced a previous glaciation, at $200 \mathrm{hPa}$ still $63 \%$, but at $300 \mathrm{hPa}$ only $13 \%$ (globally averaged numbers). When these results were implemented in the ECHAM4 climate model, the calculated effect of OAD reduces from $-0.3 \mathrm{Wm}^{-2}$ to $-0.04 \mathrm{Wm}^{-2}$, simply because many of the cirrus clouds at lower levels have nucleated ice for the first time. In this sense the results shown in Fig. 6 present upper limits of the OAD effect. However, we think that the lower limit of only $-0.04 \mathrm{Wm}^{-2}$ is likely to be a gross underestimation of the OAD effect because the trajectory calculations ignore the presence of smaller scale temperature perturbations (including in-cloud turbulence) which will increase the frequency of nucleation/evaporation cycles far beyond the result from the synoptic-scale trajectory calculation. We have at present no proper means to calculate the frequency of cirrus formation in individual air parcels.

\section{Conclusions}

Measurements of heterogeneous freezing points with various immersed dicarboxylic acids in different aqueous solutions have been presented. It was found that only oxalic acid, in the form of OAD, acts as a heterogeneous ice nucleus. The heterogeneous freezing points do not depend strongly on the oxalic acid surface area, which indicates that the heterogeneous rate coefficient is a strong function of temperature. The $\Delta T_{\text {het }}$ for the different aqueous solution is between 1.8 and $5 \mathrm{~K}$, with $\Delta T_{\text {het }}$ increasing with increasing concentration of the solution. Water-activity-based nucleation theory (Koop et al., 2000) adapted to heterogeneous ice nucleation in the immersion mode showed that the measured heterogeneous freezing points are well described by a constant offset of $\Delta a_{\mathrm{w}, \text { het }}=0.285$. We can conclude that the heterogeneous ice nucleation in the immersion mode is generally described by a constant offset $\Delta a_{\mathrm{w} \text {,het }}$ for each ice nucleus, since the same approach was already applied successfully in two other independent studies using different IN (Zuberi et al., 2002; Archuleta et al., 2005). Simulations with a microphysical box model indicate that OAD nano-crystals decrease the ice particle number density in cirrus clouds by up to $50 \%$, which leads to a reduction of the optical depth by up to $20 \%$. The net-radiative effect of cirrus clouds nucleated heterogeneously on OAD nano-crystals compared to exclusively homogeneously nucleated clouds is estimated by the ECHAM4 model to be at most $-0.3 \mathrm{Wm}^{-2}$.

These results suggest a potentially strong influence of oxalic acid on the radiation budget. However, they also give rise to several questions that should be investigated in future studies: What are the major sources for oxalic acid in the UT and how are they influenced by anthropogenic factors? Could a change in emissions of organic precursors or in climatic conditions have influenced the abundance of oxalic acid in the free troposphere?

For OAD containing particles to be active as IN, the oxalic acid must crystallize as OAD. Our DSC experiments have shown that this happens concurrently with or induced by ice freezing. In the atmosphere this means that an air parcel must have undergone a freezing/evaporation cycle to contain OAD IN. Hence, the occurrence of this type of IN depends on the history of the air parcel.

There is ample evidence that oxalic acid is contained in upper tropospheric aerosols (Narukawa et al., 2003a, and this study) and it is very likely that its mixing ratio is anthropogenically influenced. However, this does not mean that the OAD-induced heterogeneous ice nucleation discussed here must also be affected by changes in the oxalic acid mixing ratios. Rather, there could be a threshold for the OAD effect which results as follows. According to the process outlined here, the number density of OAD nuclei is solely determined by the initial homogeneous ice nucleation, i.e, independent of the oxalic acid mixing ratio. The resulting OAD IN grow subsequently via the Bergeron-Findeisen process. If oxalic acid mixing ratios change, this will affect the size of OAD IN but not their number density, and hence will not affect the ice particle number densities of second and higher generation clouds. Therefore, it is unlikely that there is a linear dependence between oxalic acid and cirrus properties. Conversely, there must be a threshold at some low mixing ratio, below which the oxalic acid concentration is too low to form OAD or the resulting IN become too small to be still efficient. However, this argument also has limitations. It ignores that OAD number densities might change through outmixing and entrainment of air in clouds. It will require future investigations to explore the consequences of mixing effects for OAD-induced ice nucleation.

Notwithstanding the answers to these questions, the present work demonstrates that oxalic acid is likely to play a considerable role in the Earth's climate system.

\section{Appendix A}

\section{Vapor pressure of aqueous oxalic acid particles}

Vapor pressures of aqueous oxalic acid solutions were obtained using a single levitated oxalic acid aqueous solution particle in an electrodynamic balance. Details of the experimental setup of the electrodynamic balance and its analytical capabilities are given in Colberg et al. (2004). For the measurements of vapor pressures of semivolatile compounds in aqueous solutions, the relative humidity in the experimental chamber is kept constant while the gas phase vapor pressure of the organic compound is kept infinitely small by means of a continuous flow of a $\mathrm{N}_{2} / \mathrm{H}_{2} \mathrm{O}$ gas mixture through the chamber. Mie resonance spectroscopy is used to monitor 
Table 3. Vapor pressure measurements ( $p_{\text {vap }}$ ) of two liquid oxalic acid droplets with an electrodynamic balance at different temperatures $(T)$ and constant relative humidities $(R H) . \rho_{\mathrm{aq}}$ is the estimated density of the aqueous oxalic acid solution.

\begin{tabular}{cccc}
\hline$T=282.7 \mathrm{~K}$ & $R H=85.0 \%$ & $T=268.2 \mathrm{~K}$ & $R H=84.5 \%$ \\
\hline$\rho_{\mathrm{aq}}=1.1 \mathrm{~g} \mathrm{~cm}^{-3}$ & $p_{\text {vap }}=5.9 \times 10^{-3} \mathrm{~Pa}$ & $\rho_{\mathrm{aq}}=1.1 \mathrm{~g} \mathrm{~cm}^{-3}$ & $p_{\text {vap }}=9.1 \times 10^{-4} \mathrm{~Pa}$ \\
$\rho_{\mathrm{aq}}=1.3 \mathrm{~g} \mathrm{~cm}^{-3}$ & $p_{\text {vap }}=5.0 \times 10^{-3} \mathrm{~Pa}$ & $\rho_{\mathrm{aq}}=1.3 \mathrm{~g} \mathrm{~cm}^{-3}$ & $p_{\text {vap }}=7.7 \times 10^{-4} \mathrm{~Pa}$ \\
\hline \multicolumn{4}{c}{$\Delta H / R=9800 \pm 500 \mathrm{~K}$} \\
\hline
\end{tabular}

the radius change of the particle due to loss of the organic compound to the gas phase (Chylek et al., 1983). To follow a resonance peak as a function of time, a point source broad band LED (centered at $585 \mathrm{~nm}$ ) is used to illuminate the particle. A spectrograph with CCD detector records the spectrum of the elastically backscattered light (Zardini et al., 2006). Thus, the radius and its change with time at a chosen temperature and relative humidity can be determined. The vapor pressure is then calculated using the evaporation equation. The vapor pressures as a function of temperature, $p_{\text {vap }}(T)$, follow the Clausius-Clapeyron equation,

$p_{\text {vap }}(T)=p_{0} \exp \left[-\frac{\Delta H}{R} \cdot\left(\frac{1}{T}-\frac{1}{T_{0}}\right)\right]$,

where $p_{0}$ is the vapor pressure of a liquid solution at the reference temperature $T_{0}$ and $\Delta H$ the evaporation enthalpy in $\mathrm{Jmol}^{-1}$. To calculate the vapor pressure from the particle radius change, the density of the aqueous oxalic acid solution has to be known. Since no accurate experimental data is available, we calculated the vapor pressures given in Table 3 for two different realistic densities for the aqueous solutions $\left(\rho_{\mathrm{aq}}\right)$. The uncertainty of the vapor pressures of $15 \%$ is mainly due to the error in absolute radius, originating from the finite resolution of the spectrograph used.

For a tropospheric aerosol containing liquid particles with an oxalic acid concentration of $2 \mathrm{wt} \%$ at cirrus temperatures, a previous nucleation event will result in the crystallization of OAD together with ice. The low OAD vapor pressure leads to the growth of the OAD crystals at the expense of the oxalic acid in the liquid particle. Thus one can estimate whether the gas phase transport from a liquid aerosol particle to a solid OAD crystal occurs on timescales of atmospheric relevance.

The growth of a spherical particle to the radius of $r_{0}$ can be described as (Fahey et al., 2001),

$r_{0}^{2}=2 V D_{\mathrm{g}}^{*}\left(n_{\mathrm{g}}-n_{\mathrm{vap}}^{\mathrm{OAD}}\right) \Delta t$,

where $V$ is the molecular volume of OAD, $D_{g}^{*}$ is the effective gas phase diffusion coefficient of oxalic acid in air, $n_{\mathrm{g}}$ and $n_{\text {vap }}^{\mathrm{OAD}}$ are the gas phase and equilibrium oxalic acid concentrations over OAD and $\Delta t$ is the time needed for a particle to grow to the size of $r_{0}$.

$D_{\mathrm{g}}^{*}$ can be expressed by the diffusion coefficient over a bulk phase $\left(D_{\mathrm{g}}\right)$ and a kinetic reduction factor due to small parti- cle radii:

$D_{\mathrm{g}}^{*}=\frac{D_{\mathrm{g}}}{1+\frac{4 D_{\mathrm{g}}}{r \overline{\mathrm{v}}}}$,

where $r$ and $\bar{v}$ are the radius and the mean thermal velocity of the particle. $D_{\mathrm{g}}$ can be estimated with the diffusion coefficient of water vapor (Pruppacher and Klett, 1997) and an adjustment factor due to the different masses of water and oxalic acid.

$D_{\mathrm{g}}=0.211 \cdot\left(\frac{T}{T_{0}}\right)^{1.94} \cdot \frac{p_{0}}{p} \cdot \sqrt{\frac{\mu_{\mathrm{H}_{2} \mathrm{O}}}{\mu_{\mathrm{OA}}}}$

where $T$ and $p$ are the temperature and pressure of the growing particle. $T_{0}$ and $p_{0}$ are $298 \mathrm{~K}$ and 1013 mbar. $\mu_{\mathrm{H}_{2} \mathrm{O}}$ and $\mu_{\mathrm{OA}}$ are the reduced masses of water molecules in air and oxalic acid molecules in air, respectively. $\bar{v}$ can be expressed as:

$\bar{v}=\sqrt{\frac{8 R T}{\pi M_{\mathrm{OA}}}}$.

Here, $M_{\mathrm{OA}}$ is the molar mass of oxalic acid.

Assuming a constant volume of the air mass, $n_{\mathrm{g}}$ can be determined by means of the ideal gas law. The rate at which the solid particles grow by gas phase transport of oxalic acid proceeds can be obtained assuming $p_{\text {vap }}^{\mathrm{OAD}}=0$ and calculating $p_{\mathrm{g}}$ for a $2 \mathrm{wt} \%$ aqueous solution based on Raoult's law and ideal solutions. Thus a new particle grows at $T=235 \mathrm{~K}$ in $\sim 33 \mathrm{~h}$ to a size of $0.1 \mu \mathrm{m}$.

\section{Appendix B}

\section{Microphysical box model}

To estimate the influence of OAD on the ice number density of cirrus clouds, the microphysical box model described by Hoyle et al. (2005) was used. So far, in this model only homogeneous ice nucleation has been considered. In the presence of an IN, such as OAD, the total ice nucleation rate, $R_{\mathrm{tot}}$, is given by

$R_{\text {tot }}(T)=j_{\text {hom }}(T) \cdot V_{\text {liquid }}+j_{\text {het }}(T) \cdot S_{\mathrm{OAD}}$,

where $j_{\text {hom }}(T)$ and $j_{\text {het }}(T)$ are the homogeneous and heterogeneous ice nucleation rate coefficients at temperature $T$, 
respectively. $V_{\text {liquid }}$ and $S_{\mathrm{OAD}}$ are the volume of the liquid droplet and the surface of the ice nucleus, which both can be determined based on field data or laboratory experiments. $j_{\text {hom }}(T)$ is described according to Koop et al. (2000), while $j_{\text {het }}(T)$ can be estimated using the DSC freezing point experiments carried out in this study.

In the DSC experiments the cooling rates and the sample volumes are equal for the homogeneous and heterogeneous ice nucleation and $\Delta T_{\text {het }}$ is rather small (see Table 2). Moreover, the width of the heterogeneous and homogeneous freezing peaks in the DSC are very similar. Therefore, the homogeneous, $R_{\text {hom }}\left(T_{\mathrm{f}}\right)$, and heterogeneous, $R_{\text {het }}\left(T_{\mathrm{f} 2}\right)$, nucleation rates are approximately equal for both experiments:

$$
\begin{aligned}
R_{\text {hom }}\left(T_{\mathrm{f}}\right) & \simeq R_{\text {het }}\left(T_{\mathrm{f} 2}\right) \\
j_{\text {hom }}\left(T_{\mathrm{f}}\right) \cdot V_{\text {liquid }} & \simeq j_{\text {het }}\left(T_{\mathrm{f} 2}\right) \cdot S_{\mathrm{OAD}} .
\end{aligned}
$$

$T_{\mathrm{f}}$ is the homogeneous freezing temperature of the reference sample and $T_{\mathrm{f} 2}$ the heterogeneous freezing temperature of the second cycle (see Table 2). $V_{\text {liquid }}$ is calculated using the mean diameter of the emulsion droplets of $4 \mu \mathrm{m}$. The surface of the OAD is determined by assuming that all oxalic acid in a particle is incorporated in a spherical crystal. Based on this assumption $j_{\text {het }}(T)$ can be estimated for the measured freezing points. Parameterization of the heterogeneous freezing temperatures in terms of a constant water activity offset with respect to the ice melting point curve as done in Sect. 3.3 allows to estimate $j_{\text {het }}$ at any given temperature and $a_{\mathrm{w}}$ by,

$j_{\text {het }}\left(a_{\mathrm{w}}, T\right)=\frac{V_{\text {liquid }}}{S_{\mathrm{OAD}}} \cdot j_{\text {hom }}\left(a_{\mathrm{w}}+\delta a_{\mathrm{w}}^{\mathrm{avg}}, T\right)$,

where $\delta a_{\mathrm{w}}^{\mathrm{avg}}=\Delta a_{\mathrm{w}, \text { hom }}-\Delta a_{\mathrm{w}, \text { het }}=0.02$ (see Fig. 2).

With these nucleation rate coefficients it is possible to calculate the total nucleation rate of an air parcel containing background aerosol particles as well as OAD IN. Aerosol properties are taken from the PACE-7 campaign over the northwestern Pacific Ocean in 2000, since in this field study, the concentration of oxalic acid (collected on Teflon filters, Narukawa et al., 2003b) as well as the size distribution of the background aerosol (Zaizen et al., 2004) have been measured at several heights in the upper troposphere. For the initial aerosol size distribution of the model, mean values of several flights at $11 \mathrm{~km}$ of the PACE-7 campaign are used. The size distribution and surface areas of the OAD nano-crystals are estimated starting from an oxalic acid concentration of uniformly $2 \mathrm{wt} \%$ in the liquid phase. Solid OAD nano-crystals that form in a first homogeneous freezing event result in an ice particle number density according to the solid lines in Fig. 5. In all nucleated ice particles, the oxalic acid is assumed to crystallize fully to OAD. The OAD particles then grow by a Bergeron-Findeisen type process at the expense of the liquid aerosol particles.

In the atmosphere, gravity waves and turbulence lead to mesoscale cooling rates which are in most cases clearly larger than the synoptic scale cooling rates (Hoyle et al.,
2005). One has to take into account that the cooling rate at the moment of the nucleation is crucial for the nucleation process itself. For the SUCCESS campaign (Subsonic Aircraft: Contrail and Cloud Effects Special Study) we have converted measurements of the vertical winds to mesoscale cooling rates (black dashed line in Fig. 4). The same MonteCarlo techniques as in Hoyle et al. (2005) are used here to simulate the number density of ice particles by homogeneous nucleation alone and by homogeneous together with heterogeneous nucleation. For this purpose a simplified synoptic scale trajectory with a cooling rate of $0.2 \mathrm{Kh}^{-1}$ was assumed, and this trajectory was calculated repeatedly (4000 times) with superimposed mesoscale temperature fluctuations to obtain the ice number density for homogeneous ice nucleation (red line in Fig. 5). For the subsequent heterogeneous nucleation cycle, the number density of the OAD and their surface area distribution were calculated by modeling their formation during a first freezing cycle as explained above. The number density of OAD in each simulation was chosen stochastically from the calculated ice number density after the first homogeneous freezing cycle. This time the trajectory was calculated 4000 times with varying overlaying mesoscale fluctuations (see dashed lines in Fig. 5).

\section{Appendix C}

\section{Global climate model (ECHAM4)}

The cirrus scheme described by Lohmann and Kärcher (2002) was used for the ECHAM4 model simulation. The homogeneous freezing parameterization uses temperature, aerosol number density, and updraft speeds empirically corrected for subgrid-scale variability to determine the number concentration of newly formed ice crystals, $n_{\mathrm{i}}$, in a given model time step $\Delta t$. The evaluation of $n_{\mathrm{i}}$ is based on a nucleation rate expression that links the rate with temperature and water activity in the freezing aerosol (Koop et al., 2000). The latter is approximated by the ambient relative humidity in order to obtain an analytical solution. For homogeneous freezing to occur within one time step, the adiabatic cooling from a constant updraft speed has to exceed the critical supersaturation. The climate model then uses $n_{\mathrm{i}}$ and integrates prognostic equations for the cloud ice mass mixing ratio and ice crystal number concentrations. The climate model simulation was conducted in T30 horizontal resolution $\left(3.75^{\circ} \times 3.75^{\circ}\right)$ with 19 vertical levels and a 30 min time-step for one full year after an initial spin-up of 3 months using climatological sea surface temperatures and sea ice extent.

Acknowledgements. We are grateful for support by the Swiss National Fund in various projects and by the European Commission through the integrated project SCOUT-O3.

Edited by: Y. Rudich 


\section{References}

Apelblat, A. and Manzurola, E.: Solubility of malonic, oxalic, succinic, adipic, malic, citric, and tartaric acids in water from 278.15 to 338.15 K, J. Chem. Thermodyn., 19, 317-320, 1987.

Archuleta, C. M., DeMott, P. J., and Kreidenweis, S. M.: Ice nucleation by surrogates for atmospheric mineral dust and mineral dust/sulfate particles at cirrus temperatures, Atmos. Chem. Phys., 5, 2617-2634, 2005.

Baker, M. B.: Cloud microphysics and climate, Science, 276, 10721078, 1997.

Bertram, A. K., Koop, T., Molina, L. T., and Molina, M. J.: Ice formation in $\left(\mathrm{NH}_{4}\right)_{2} \mathrm{SO}_{4}-\mathrm{H}_{2} \mathrm{O}$ particles, J. Phys. Chem. A, 104, 584-588, 2000.

Braban, C. F., Carroll, M. F., Styler, S. A., and Abbatt, J. P. D.: Phase transitions of malonic and oxalic acid aerosols, J. Phys. Chem. A, 107, 6594-6602, 2003.

Chebbi, A. and Carlier, P.: Carboxylic acids in the troposphere, occurrence, sources, and sinks: A review, Atmos. Environment, 30, 4233-4249, 1996.

Chen, Y., Kreidenweis, S. M., McInnes, L. M., Rogers, D. C., and DeMott, P. J.: Single particle analyses of ice nucleating aerosols in the upper troposphere and lower stratosphere, Geophys. Res. Lett., 25, 1391-1394, 1998.

Choi, M. Y. and Chan, C. K.: Continuous measurements of the water activities of aqueous droplets of water-soluble organic compounds, J. Phys. Chem. A, 106, 4566-4572, 2002.

Chylek, P., Ramaswany, V., Ashkin, A., and Dziedzic, J. M.: Simultaneous determination of refractive index and size of spherical dielectric particles from light scattering data, Appl. Opt., 22, 2302-2307, 1983.

Clegg, S. L., Brimblecombe, P., and Wexler, A. S.: Thermodynamic model of the system $\mathrm{H}^{+}-\mathrm{NH}_{4}^{+}-\mathrm{SO}_{4}^{2-}-\mathrm{NO}_{3}^{-}-\mathrm{H}_{2} \mathrm{O}$ at tropospheric temperatures, J. Phys. Chem. A, 102, 2137-2154, 1998.

Colberg, C. A., Krieger, U. K., and Peter, T.: Morphological investigations of single levitated $\mathrm{H}_{2} \mathrm{SO}_{4} / \mathrm{NH}_{3} / \mathrm{H}_{2} \mathrm{O}$ aerosol particles during deliquescence/efflorescence experiments, J. Phys. Chem. A, 108(14), 2700-2709, 2004.

Cziczo, D. J., DeMott, P. J., Brooks, S. D., Prenni, A. J., Thomson, D. S., Baumgardner, D., Wilson, J. C., Kreidenweis, S. M., and Murphy, D. M.: Observations of organic species and atmospheric ice formation, Geophys. Res. Lett., 31, L12116, doi:10.1029/2004GL019822, 2004a.

Cziczo, D. J., Murphy, D. M., Hudson, P. K., and Thomson, D. S.: Single particle measurements of the chemical composition of cirrus ice residue during CRYSTAL-FACE, J. Geophys. Res., 109, D04201, doi:10.1029/2003JD004032, 2004b.

DeMott, P. J., Chen, Y., Kreidenweis, S. M., Rogers, D. C., and Sherman, D. E.: Ice formation by black carbon particles, Geophys. Res. Lett., 26, 2429-2432, 1999.

DeMott, P. J., Cziczo, D. J., Prenni, A. J., Murphy, D. M., Kreidenweis, S. M., Thomson, D. S., Borys, R., and Rogers, D. C.: Measurements of the concentration and composition of nuclei for cirrus formation, Proc. Natl. Acad. Sci., 100, 14 655-14 660, 2003.

Ervens, B., Feingold, G., Frost, G. J., and Kreidenweis, S. M.: A modeling study of aqueous production of dicarboxylic acids: 1 . Chemical pathways and speciated organic mass production, J. Geophys. Res., 109, D15205, doi:10.1029/2003JD004387, 2004.
Facchini, M. C., Mircea, M., Fuzzi, S., and Charlson, R. J.: Cloud albedo enhancement by surface-active organic solutes in growing droplets, Nature, 401, 257-259, 1999.

Fahey, D. W., Gao, R. S., Carslaw, K. S., Kettleborough, J., Popp, P. J., Northway, M. J., Holecek, J. C., Ciciora, S. C., McLaughlin, R. J., Thompson, T. L., Winkler, R. H., Baumgardner, D. G., Gandrud, B., Wennberg, P. O., Dhaniyala, S., McKinney, K., Peter, T., Salawitch, R. J., Bui, T. P., Elkins, J. W., Webster, C. R., Atlas, E. L., Jost, H., Wilson, J. C., Herman, R. L., Kleinböhl, A., and von König, M.: The detection of large $\mathrm{HNO}_{3}$-containing particles in the winter Arctic stratosphere, Science, 29, 10261031, 2001.

Graham, B., Mayol-Bracero, O. L., Guyon, P., Roberts, G. C., Decesari, S., Facchini, M. C., Artaxo, P., Maenhaut, W., Köll, P., and Andreae, M. O.: Water-soluble organic compounds in biomass burning aerosols over Amazonia 1. Characterization by NMR and GC-MS, J. Geophys. Res., 107(D20), 8047, doi:10.1029/2001JD000336, 2002.

Hansen, A. R. and Beyer, K. D.: Experimentally determined thermochemical properties of the malonic acid/water system: Implications for atmospheric aerosols, J. Phys. Chem. A, 108, 34573466, 2004.

Hoyle, C. R., Luo, B. P., and Peter, T.: The origin of high ice crystal number densities in cirrus clouds, J. Atmos. Sci., 62, 2568-2579, 2005.

Hung, H. M., Malinowski, A., and Martin, S. T.: Kinetics of heterogeneous ice nucleation on the surfaces of mineral dust cores inserted into aqueous ammonium sulfate particles, J. Phys. Chem. A, 107, 1296-1306, 2003.

Kärcher, B. and Koop, T.: The role of organic aerosols in homogeneous ice formation, Atmos. Chem. Phys., 5, 703-714, 2005.

Kärcher, B. and Lohmann, U.: A parameterization of cirrus cloud formation: Heterogeneous freezing, J. Geophys. Res., 108(D14), 4402, doi:10.1029/2002JD003220, 2003.

Kawamura, K. and Ikushima, K.: Seasonal changes in the distribution of dicarboxylic acids in the urban atmosphere, Environ. Sci. Technol., 27, 2227-2235, 1993.

Kawamura, K. and Sakaguchi, F.: Molecular distributions of water soluble dicarboxylic acids in marine aerosols over the $\mathrm{Pa}$ cific Ocean including tropics, J. Geophys. Res., 104, 3501-3509, 1999.

Koop, T.: Homogeneous ice nucleation in water and aqueous solutions (Review article), Z. Phys. Chem., 218, 1231-1258, 2004.

Koop, T., Ng, H. P., Molina, L. T., and Molina, M. J.: A new optical technique to study aerosol phase transitions: The nucleation of ice from $\mathrm{H}_{2} \mathrm{SO}_{4}$ aerosols, J. Phys. Chem. A, 102, 8924-8931, 1998.

Koop, T., Bertram, A. K., Molina, L. T., and Molina, M. J.: Phase transitions in aqueous $\mathrm{NH}_{4} \mathrm{HSO}_{4}$ solutions, J. Phys. Chem. A, 103, 9042-9048, 1999.

Koop, T., Luo, B. P., Tsias, A., and Peter, T.: Water activity as the determinant for homogeneous ice nucleation in aqueous solutions, Nature, 406, 611-614, 2000.

Legrand, M., Preunkert, S., Galy-Lacaux, C., Liousse, C., and Wagenbach, D.: Atmospheric year-round records of dicarboxylic acids and sulfate at three French sites located between 630 and $4360 \mathrm{~m}$ elevation, J. Geophys. Res., 110, D13302, doi:10.1029/2004JD005515., 2005.

Lohmann, U. and Feichter, J.: Global indirect aerosol effects: A 
review, Atmos. Chem. Phys., 5, 715-737, 2005.

Lohmann, U. and Kärcher, B.: First interactive simulations of cirrus clouds formed by homogeneous freezing in the ECHAM general circulation model, J. Geophys. Res., 107(10), 4105, doi:10.1029/2001JD000767, 2002.

Marcolli, C., Luo, B. P., and Peter, T.: Mixing of the organic aerosol fractions: Liquids as the thermodynamically stable phases, J. Phys. Chem. A, 108, 2216-2224, 2004a.

Marcolli, C., Luo, B. P., Peter, T., and Wienhold, F. G.: Internal mixing of the organic aerosol by gas phase diffusion of semivolatile organic compounds, Atmos. Chem. Phys., 4, 25932599, 2004b.

Middlebrook, A. M., Murphy, D. M., and Thomson, D. S.: Observations of organic material in individual marine particles at Cape Grim during the First Aerosol Characterization Experiment (ACE 1), J. Geophys. Res., 103(D13), 16475-16483, 1998.

Murphy, D. M., Thomson, D. S., and Mahoney, M. J.: In situ measurements of organics, meteoric material, mercury and other elements in aerosols at 5 to 19 kilometers, Science, 282, 1664-1669, 1998.

Narukawa, M., Kawamura, K., Anlauf, K. G., and Barrie, L. A.: Fine and coarse modes of dicarboxylic acids in the arctic aerosols collected during the Polar Sunrise Experiment 1997, J. Geophys. Res., 108(D18), 4575, doi:10.1029/2003JD003 646, 2003a.

Narukawa, M., Kawamura, K., Okada, K., Zaizen, Y., and Makino, Y.: Aircraft measurements of dicarboxylic acids in the free tropospheric aerosol over the western central North Pacific, Tellus, 55B, 777-786, 2003b.

Novakov, T. and Penner, J. E.: Large contribution of organic aerosols to cloud-condensation-nuclei concentrations, Nature, $365,823-826,1993$

Novakov, T., Hegg, D. A., and Hobbs, P. V.: Airborne measurements of carbonaceous aerosols on the East Coast of the United States, J. Geophys. Res., 102(D25), 30 023-30 030, 1997.

Parsons, M. T., Mak, J., Lipetz, S. R., and Bertram, A. K.: Deliquescence of malonic, succinic, glutaric, and adipic acid particles, J. Geophys. Res., 109, D06212, doi:10.1029/2003JD004075, 2004.

Prenni, A. J., DeMott, P. J., Kreidenweis, S. M., Sherman, D. E., Russell, L. M., and Ming, Y.: The effects of low molecular weight dicarboxylic acids on cloud formation, J. Phys. Chem. A, 105, 11240-11248, 2001.
Pruppacher, H. R. and Jaenicke, R.: The processing of water vapor and aerosols by atmopsheric clouds, a global estimate, Atmos. Res., 38, 283-295, 1995.

Pruppacher, H. R. and Klett, J. D.: Microphysics of clouds and precipitation, Kluwer, Dordrecht, 1997.

Rasmussen, D. H. and MacKenzie, A. P.: Effect of solute on icesolution interfacial free energy; calculation from measured homogeneous nucleation temperatures, in: Water structure at the water polymer interface, edited by: Jellinek, H. H. G., 126-145, Plenum Press, New York, 1972.

Stephen, H. and Stephen, T.: Solubilities of inorganic and organic compounds, Pergamon Press, Oxford, 1963.

Stephen, H. and Stephen, T. (Eds.): Solubilities of inorganic and organics compounds, vol. 2, part 1, 500-501, Pergamon Press/The Macmillon Company, New York, 1964.

Yao, X. H., Fang, M., and Chan, C. K.: Size distributions and formation of dicarboxylic acids in atmospheric particles, Atmos. Environment, 36, 2099-2107, 2002.

Zaizen, Y., Okada, K., Ikegami, M., Sawa, Y., and Makino, Y. Number-size distributions of aerosol particles in the free troposphere over the Northwestern Pacific ocean-Influence of Asian outflow and tropical air transport, J. Meteo. Soc. Japan, 82, 1147-1160, 2004.

Zardini, A. A., Krieger, U. K., and Marcolli, C.: White light Mie resonance spectroscopy used to measure very low vapor pressures of substances in aqueous solution aerosol particles, Opt. Express, 14, 6951-6962, 2006.

Zobrist, B., Weers, U. G., and Koop, T.: Ice nucleation in aqueous solutions of poly[ethylene glycol] with different molar mass, J. Chem. Phys, 118, 10 254-10 261, 2003.

Zuberi, B., Bertram, A. K., Koop, T., Molina, L. T., and Molina, M. J.: Heterogeneous freezing of aqueous particles induced by crystallized $\left(\mathrm{NH}_{4}\right)_{2} \mathrm{SO}_{4}$, Ice, and Letovicite, J. Phys. Chem. A, 105, 6458-6464, 2001.

Zuberi, B., Bertram, A. K., Cassa, C. A., Molina, L. T., and Molina, M. J.: Heterogeneous nucleation of ice in $\left(\mathrm{NH}_{4}\right)_{2} \mathrm{SO}_{4}-\mathrm{H}_{2} \mathrm{O}$ particles with mineral dust immersions, Geophys. Res. Lett., 29(10), 1504, doi:10.1029/2001GL01489, 2002. 